\title{
Insights into the Mechanism of an Allylic Arylation Reaction via Photoredox Coupled Hydrogen Atom Transfer
}

\author{
Ethan H. Spielvogel, Bernard G. Stevenson, Michael J. Stringer, John R. Swierk
}

Department of Chemistry, State University of New York at Binghamton, Vestal, NY 13850

\begin{abstract}
Despite widespread use as a synthetic method, as well as rapid expansion of substrate scope, the precise mechanism and kinetics of photoredox coupled hydrogen atom transfer (HAT) reactions remain poorly understood. This results from a lack of detailed kinetic information, as well as the identification of side reactions and products. In this report, a mechanistic study of a prototypical tandem photoredox/HAT reaction coupling cyclohexene and 1,4-Dicyanobenzene (DCB) using an Ir(ppy) 3 photocatalyst and thiol HAT catalyst is reported. Through a combination of electrochemical, photochemical, and spectroscopic measurements, key unproductive pathways and side products are identified and rate constants for main chemical steps are extracted. The reaction quantum yield was found to decline rapidly over the course of the 20-hour reaction. A previously unreported cyanohydrin side product was identified and thought to play a key role as proton acceptor in the reaction. Transient absorption spectroscopy (TAS) suggested a reaction mechanism that involves trapping of the DCB radical anion by cyclohexene with HAT occurring as the final step via a cooperative HAT step. Kinetic modeling of the reaction, using rate constants derived from TAS, demonstrates that the efficiency of the reaction is limited by parasitic absorption and unproductive quenching between excited $\operatorname{Ir}(\mathrm{ppy})_{3}$ and the cyanohydrin photoproduct.
\end{abstract}

\section{INTRODUCTION}

In recent years, photoredox reactions have rapidly grown in scope and application to small molecule and pharmaceutical synthesis. Photoredox reactions harness the energy in light to generate short-lived excited states, which in turn can undergo electron transfer to initiate a reaction via the generation of a radical intermediate. ${ }^{1}$ As an extension, tandem photoredox/organocatalytic methods provide an attractive synthetic approach for the selective activation of stable $\mathrm{C}-\mathrm{H}$ bonds. ${ }^{1}$ This one-pot method leverages both the strong oxidizing or reducing potential of the excited photocatalyst and couples it with an organocatalyst to achieve the desired transformation. ${ }^{1}$

A particularly successful class of tandem photoredox/organocatalytic reactions utilize hydrogen atom transfer (HAT) catalysts as the co-catalyst. ${ }^{1-}$ ${ }^{7}$ In this context, HAT involves the simultaneous transfer of a proton and electron to generate a reactive radical species, which can then be captured via radical coupling. Thiol HAT catalysts are commonly utilized in tandem photoredox/HAT methods. Most mechanistic proposals involve oxidation of the thiol moiety by the photocatalyst to generate a thiyl radical with the assistance of an ancillary base. These thiyl radicals then can act as potent hydrogen atom abstractors. In general,
HAT catalysts achieve selectivity by targeting weakened $\mathrm{C}-\mathrm{H}$ and $\mathrm{X}-\mathrm{H}$ bonds $(\mathrm{X}=\mathrm{S}, \mathrm{N}, \mathrm{O})$, including those in olefins, tertiary amines, dihydrofuran, piperidines, and benzylic ethers. ${ }^{1}$

Despite the importance of tandem photoredox/HAT reactions, the nature of these radical reactions makes their precise mechanism elusive. Nocera and coworkers characterized the mechanism of a photoredox/HAT hydroamidation reaction through transient absorption spectroscopy (TAS), quantum yield (QY) measurements, quenching studies, and DFT calculations. ${ }^{2}$ Through their findings they were able to tune the quantum efficiency of the reaction by modifying the organocatalyst to minimize the rates of deactivation pathways, such as back electron transfer and unproductive HAT. In a more recent study, Knowles, Nocera, and coworkers examined a photoredox catalyzed anti-Markovnikov radical addition of aminium radical cations to alkenes, which yielded the tertiary amine product. ${ }^{4}$ By studying the mechanism of the transformation, they were able to identify the source of the hydroamination selectivity, as well as which steps in the mechanism limited the overall reaction QY. With this knowledge they were able to tune the HAT catalyst and achieve a significant increase in QY. Other detailed mechanistic studies on photoredox 
reactions have likewise led to significant improvements in QY and scope. . $^{814}$

We recently reported on the mechanism of a photoredox-catalyzed $\alpha$-aminoarylation reaction involving 1,4-dicyanobenzene (DCB) and N-phenylpyrrolidine. ${ }^{15}$ Using TAS, we found that deprotonation of the $N$-Phenylpyrrolidine radical cation at the alpha position was the slowest step in the reaction. However, kinetic modeling demonstrated that the kinetics did not significantly limit the reaction. Instead, the QY of the reaction was limited by light scattering off an insoluble base and parasitic absorption by a ground state donoracceptor complex between DCB and N-phenylpyrrolidine. The latter limitation was particularly problematic as $\sim 44 \%$ of incoming photons are absorbed by the donor-acceptor complex and wasted. Additionally, steady state photochemical and electrochemical data suggested that DCB played a role as the initial proton acceptor in the reaction and then transferred a proton to sodium acetate on a slower timescale.

Scheme 1. Allylic Arylation of Cyclohexene with Tandem Photoredox-HAT Catalysis

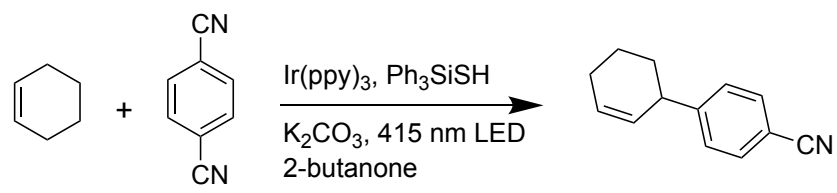

Inspired by our recent work, we report on a related coupling between electron deficient arenes and cycloalkenes to yield allylarenes via a tandem photoredox/HAT reaction originally reported by MacMillan and coworkers ${ }^{5}$ The allylarene moiety is prevalent in pharmaceutical chemistry and natural product synthesis, making it a particularly attractive candidate for mechanistic studies. ${ }^{5,16}$ In the original mechanistic proposal by MacMillan and coworkers, DCB is reduced by photoexcited $\operatorname{Ir}(\mathrm{ppy})_{3}$ to generate a radical anion (DCB--). ${ }^{5} \mathrm{Ox}-$ idation and deprotonation of a thiol HAT catalyst, $\mathrm{Ph}_{3} \mathrm{SiSH}$, regenerates the ground state $\operatorname{Ir}(\mathrm{ppy})_{3}$ and results in a reactive thiyl radical. ${ }^{5}$ This thiyl radical is then proposed to abstract a hydrogen from cyclohexene at the allylic position, followed by coupling between the neutral cyclohexenyl radical and $\mathrm{DCB} \cdot-$ with the loss of $\mathrm{CN}$ - to generate a new C-C bond. ${ }^{5}$ In this work, we utilize a combination of TAS and QY measurements to map productive and unproductive reaction pathways and assign rate constants for each step. Additionally, we utilized electrochemistry and NMR binding studies to understand the role of the ancillary base, $\mathrm{K}_{2} \mathrm{CO}_{3}$, specifically identifying the formation and importance of a previously unrecognized cyanohydrin. Finally, kinetic modeling studies demonstrate how parasitic absorption and competitive quenching limit the efficiency of the reaction.

\section{RESULTS AND DISCUSSION}

Steady State Photochemical Studies. Efficient allylic arylation of cyclohexene was achieved at high product yields (87\%) and with nearly complete conversion of DCB $(\sim 100 \%)$ after $24 \mathrm{hr}$ of illumination. The max product yield was in good agreement with those of MacMillan and co-workers $(93 \%) .{ }^{5}$ The discrepancy could be due to differences in reaction setup, light source, and solvent. The quantum yield of reaction was determined at various points throughout the course of the reaction (Figure 1). A larger margin of error for yield measurements was observed at early times due to quantitative NMR being less sensitive at low concentrations of analyte.

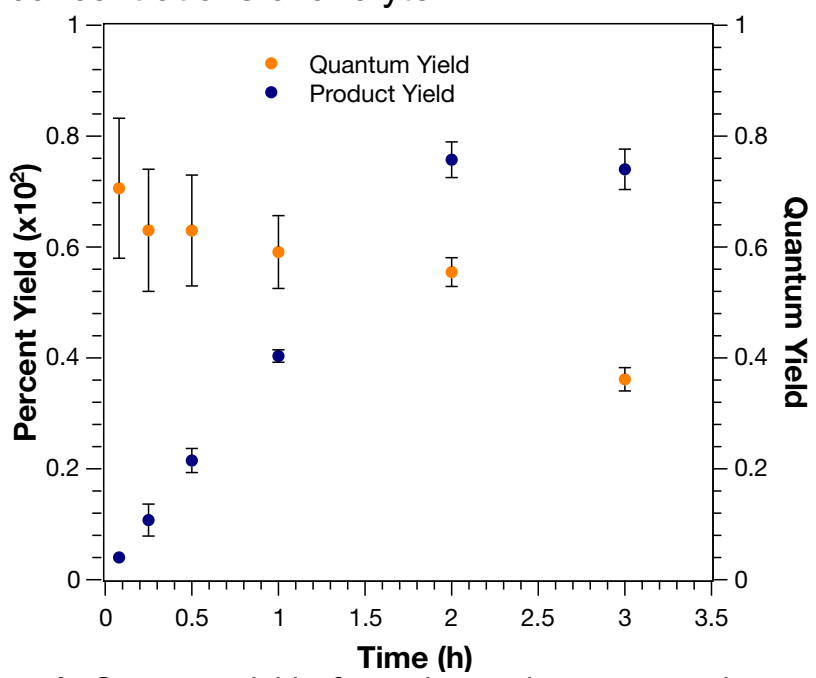

Figure 1. Quantum yield of reaction and percent product yield from $t=0$ to $t=3$ hours including standard error for three trials

Over the course of the reaction, the QY ranged from 0.70 at early times to 0.36 at 3 hours. Here, the $Q Y$ of the reaction is defined as the ratio between moles of product and moles of photons absorbed. A result of between 0.70 and 0.36 is consistent with a non-radical chain mechanism and at early times, is on the higher end of these reactions, which often range from 0.02 to $0.50 .^{3}$, 18-20

In the absence of $\mathrm{K}_{2} \mathrm{CO}_{3}$, the reaction proceeded with a lower product yield (64\% after 24 h) but with full conversion of DCB $(\sim 100 \%) . \mathrm{K}_{2} \mathrm{CO}_{3}$ is thought to assist in the deprotonation of $\mathrm{Ph}_{3} \mathrm{SiSH}$ to yield an activated thiyl radical capable of hydrogen atom abstraction. ${ }^{5}$ Electrochemically, we observe a shift to a lower oxidation potential for $\mathrm{Ph}_{3} \mathrm{SiSH}$ when in the presence of $\mathrm{K}_{2} \mathrm{CO}_{3}$ 
(Figure S1). However, if $\mathrm{K}_{2} \mathrm{CO}_{3}$ is the sole base present and does not regenerate, then the max possible yield is $10 \%$, as there are only 0.05 equivalents of the base in the reaction. This suggests the presence of an additional base, which could be one of the coupling partners or a species generated over the course of the reaction. We observed the formation of 2-butanone cyanohydrin by NMR (Figure S2-S3) over the course of the reaction, which we propose functions as a base. ${ }^{21}$ The cyanohydrin likely forms as a result of cyanide ions released from DCB reacting with 2-butanone, the reaction solvent. Using quantitative ${ }^{1} \mathrm{H}$ NMR, we plotted the generation of the cyanohydrin over time against the formation of product (Figure 2). After an initial lag in cyanohydrin formation, it was observed that cyanohydrin formation tracked with product formation. This would support its role as either the primary base after the depletion of $\mathrm{K}_{2} \mathrm{CO}_{3}$ or as a secondary base to replenish the carbonate base.

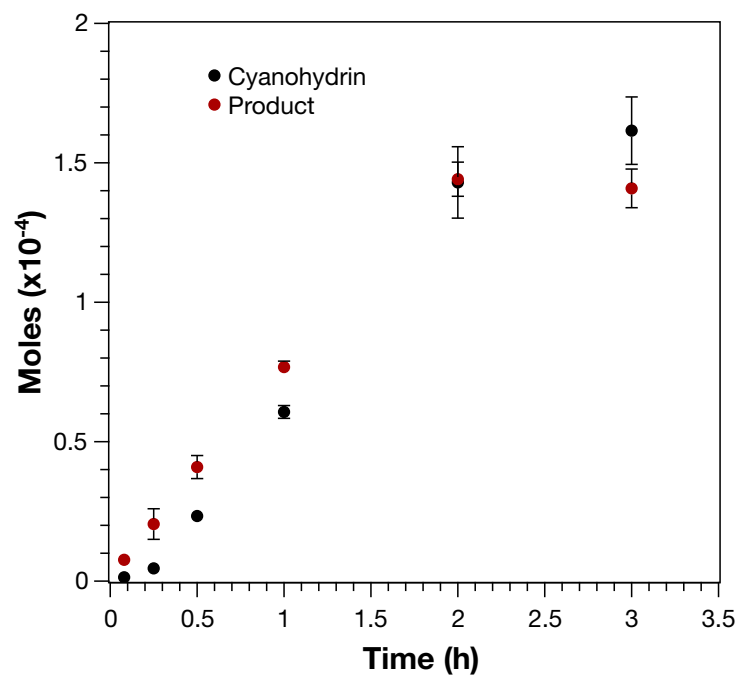

Figure 2. Formation of cyanohydrin and product from $t=0$ to $\mathrm{t}=3$ hours with standard error among three trials.

Similar to our previous work, we observed a species that absorbs broadly across the visible spectrum when $\mathrm{Ph}_{3} \mathrm{SiSH}$ and $\mathrm{K}_{2} \mathrm{CO}_{3}$ are mixed (Figure S4-5). ${ }^{15}$ Though we cannot specify the exact nature of this species, NMR binding studies demonstrate an interaction between $\mathrm{Ph}_{3} \mathrm{SiSH}$ and $\mathrm{K}_{2} \mathrm{CO}_{3}$ (Figure S6), suggesting it may interact with $\mathrm{Ph}_{3} \mathrm{SiSH}$ in the ground state, which could assist in HAT to generate the thiyl radical. While the molar extinction coefficient at $415 \mathrm{~nm}$ of this species is significant less than $\operatorname{Ir}(\mathrm{ppy})_{3}$, at reaction concentration of $\mathrm{Ph}_{3} \mathrm{SiSH}$ and $\mathrm{K}_{2} \mathrm{CO}_{3}$ the absorption at $415 \mathrm{~nm}$ is sufficiently high to compete with $\operatorname{Ir}(\mathrm{ppy})_{3}$ for photons. From the absorption spectrum of this species, it was determined that $17.5 \%$ of the incoming photons were absorbed by the $\mathrm{Ph}_{3} \mathrm{SiSH} / \mathrm{K}_{2} \mathrm{CO}_{3}$ species instead of $\operatorname{Ir}(\mathrm{ppy})_{3}$.
Electron Transfer Studies. Stern-Volmer quenching studies were carried out with DCB to establish the initial electron acceptor. The rate of quenching for DCB was found to be $1.2 \times 10^{-9} \mathrm{M}^{-1}$ $\mathrm{s}^{-1}$ while the rate for $\mathrm{Ph}_{3} \mathrm{SiSH}$ was found to be a $\mathrm{k}_{\mathrm{q}}$ of $5.1 \times 10^{7} \mathrm{M}^{-1} \mathrm{~s}^{-1}$. The slow quenching rate, combined with the large excess of DCB compared to $\mathrm{Ph}_{3} \mathrm{SiSH}$, suggest that quenching by the thiol is insignificant in the overall reaction efficiency. Quenching studies for $\mathrm{Ph}_{3} \mathrm{SiSH}$ in the presence of $\mathrm{K}_{2} \mathrm{CO}_{3}$ were unsuccessful due to spectral overlap with $\operatorname{Ir}(\text { ppy })_{3}$.

Using TAS, we were able to initiate the reaction and observe the generation of intermediates in real time. Initial electron transfer between excited $\operatorname{Ir}(\mathrm{ppy})_{3}$ and DCB is clearly seen in the transient absorption spectrum at 200 ns (Figure S8). The transient absorbance at wavelengths longer than $500 \mathrm{~nm}$, as well as the bleach at wavelengths shorter than $400 \mathrm{~nm}$, is a clear indicator for the formation of $\operatorname{Ir}(\mathrm{IV})$. The increase in absorption at $440 \mathrm{~nm}$ is characteristic of DCB $\bullet-{ }^{15}$ We found that we were able to simulate the transient spectrum by adding together the difference spectra for oxidized $\operatorname{Ir}(\text { ppy })_{3}(3.1 \mu \mathrm{M})$, DCB - $(3.4 \mu \mathrm{M})$, and $\mathrm{Ph}_{3} \mathrm{SiS} \cdot(0.3 \mu \mathrm{M})$. The presence of $\mathrm{Ph}_{3} \mathrm{SiS} \cdot$ at early timescales demonstrates efficient oxidation of $\mathrm{Ph}_{3} \mathrm{SiSH}$ by $\mathrm{Ir}(\mathrm{IV})$. Kinetic modeling suggests a rate constant of $5 \times 10^{8} \mathrm{M}^{-1} \mathrm{~s}^{-1}$ for this oxidation $\left(\mathrm{k}_{\mathrm{ox}}\right)$.

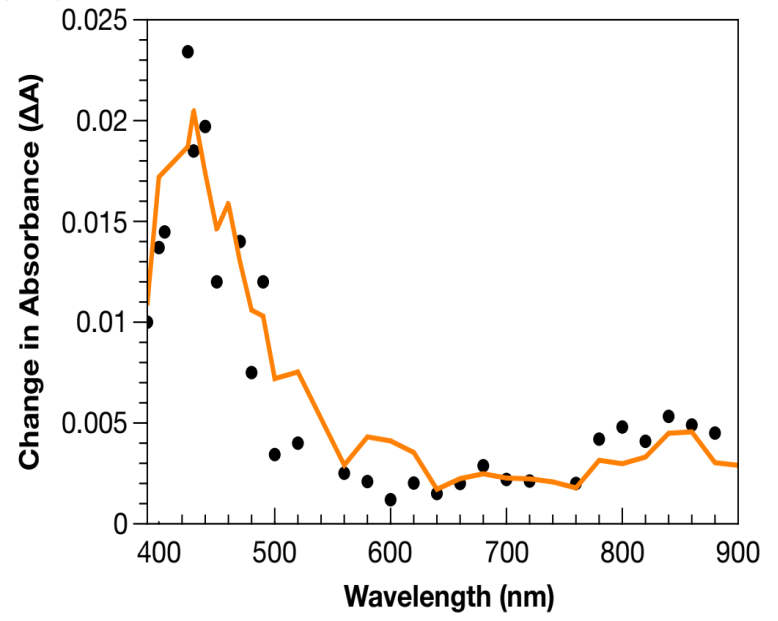

Figure 3. Change in absorption at $1 \mu \mathrm{s}$ (black dot) and sum of difference spectra (orange line) for $3.4 \mu \mathrm{M}$ DCB•-, $3.1 \mu \mathrm{M} \operatorname{Ir}(\mathrm{IV})$, and $0.3 \mu \mathrm{M}$ Ph3SiS•

By $1 \mu \mathrm{s}$, the transient spectrum no longer shows the presence of $\left[\operatorname{Ir}(\mathrm{ppy})_{3}\right]^{+}$, suggesting that it has been regenerated via oxidation of $\mathrm{Ph}_{3} \mathrm{SiSH}$. Instead, we observe a broad absorption feature from $400-600 \mathrm{~nm}$ and a smaller absorption feature from $700-900 \mathrm{~nm}$ (Figure 3). Much of the $400-600 \mathrm{~nm}$ feature can be assigned to $\mathrm{Ph}_{3} \mathrm{SiS}$ and DCB --, while the absorbance at longer wavelengths is consistent with $\left[\mathrm{DCB}_{2}\right] \bullet-{ }^{15} \mathrm{We}$ 
previously observed that $\mathrm{DCB} \cdot-$ converts to $\left[\mathrm{DCB}_{2}\right]^{\bullet}-$ over time and that it is $\left[\mathrm{DCB}_{2}\right]^{\bullet}-$ that is the competent coupling partner. The $1 \mu \mathrm{s}$ transient spectrum could be satisfactorily simulated by adding together the difference spectra for $\mathrm{Ph}_{3} \mathrm{SiS}$ $(3.4 \mu \mathrm{M}), \mathrm{DCB} \bullet-(3.08 \mu \mathrm{M})$, and $\left[\mathrm{DCB}_{2}\right] \bullet-(0.32$ $\mu \mathrm{M})$.

By $10 \mathrm{~ms}$, the only species we observe is $\mathrm{Ph}_{3} \mathrm{SiS} \cdot$ (Figure S9), which suggests that the consumption of $\mathrm{DCB} \cdot-$ and $\left[\mathrm{DCB}_{2}\right]^{\circ}-$ occurs on a shorter timescale than the disappearance of $\mathrm{Ph}_{3} \mathrm{SiS}$. This is confirmed by the single wavelength traces at $480 \mathrm{~nm}$, specific to $\mathrm{Ph}_{3} \mathrm{SiS} \cdot$, and $780 \mathrm{~nm}$, specific to $\left[\mathrm{DCB}_{2}\right]^{\circ-}$ (Figure 4). The absorbance related to $\left[\mathrm{DCB}_{2}\right]^{\circ}-$ is largely gone by $200 \mu \mathrm{s}$, while the absorbance related to $\mathrm{Ph}_{3} \mathrm{SiS}$ only begins to decay at that point, suggesting consumption of $[\mathrm{DCB}]_{2}{ }^{-}-$before $\mathrm{Ph}_{3} \mathrm{SiS} \cdot$. In the original mechanistic proposal from Cuthbertson and MacMillan, $\mathrm{Ph}_{3} \mathrm{SiS} \cdot$ abstracts a hydrogen from cyclohexene and then the cyclohexenyl radical and DCB - - undergo a coupling step. ${ }^{5}$ In that case, we would expect to observe the disappearance of $\mathrm{Ph}_{3} \mathrm{SiS} \cdot$ to be either faster or simultaneous with the disappearance of $\left[\mathrm{DCB}_{2}\right]^{\bullet}-$. Instead, we propose that the radical anion is first trapped by cyclohexene and that hydrogen abstraction occurring as the final step.

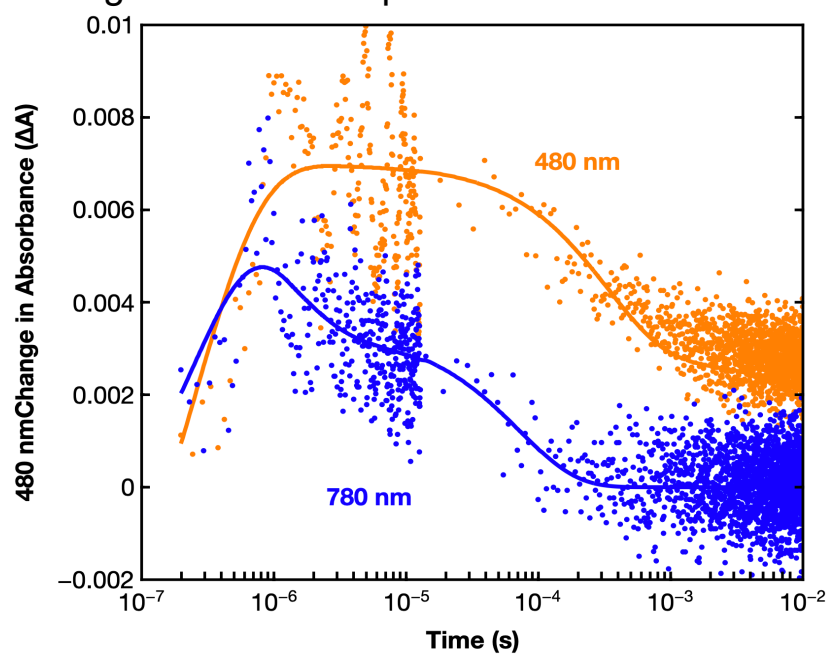

Figure 4. Single wavelength kinetic traces at $480 \mathrm{~nm}$ and $780 \mathrm{~nm}$ for various timescales.

In order to probe this hypothesis and extract kinetic information, we developed a kinetic model for the reaction that had the $\left[\mathrm{DCB}_{2}\right]^{\bullet}-$ radical anion first trapped by cyclohexene and hydrogen abstraction occurring afterwards. We also observed

Scheme 2. Mechanism of photoredox catalyzed allylic arylation of alkenes.

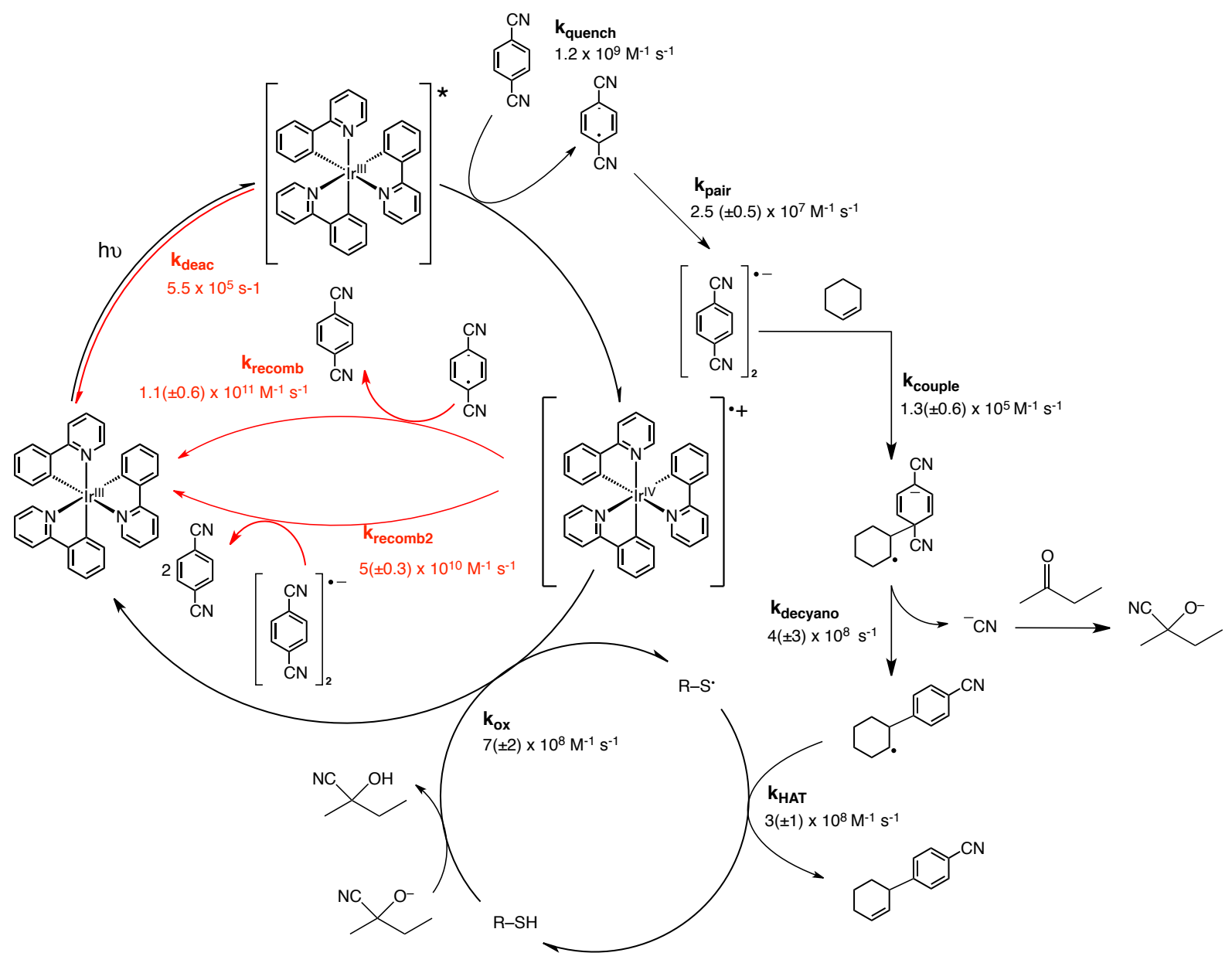


that it was also necessary to include a decyanation step, though the model produces satisfactory results with the decyanation step in place before or after $\left[\mathrm{DCB}_{2}\right] \cdot-$ trapping by cyclohexene. In our model, hydrogen abstraction thus occurs from a radical species in a cooperative HAT step. ${ }^{22}$ It is also important to note that in our model, the double bond shifts over by one carbon, which disagrees with the original mechanistic proposal. We note that in the original report, use of unsymmetric alkenes produced a variety of isomers, which may be explained by our results. In addition, we also cannot rule out that for some alkenes, abstraction of allylic hydrogen before coupling with the radical ion may be preferred for steric or electronic reasons or, that for some substrates, multiple reaction mechanisms may be simultaneously accessible.

The model described above was fit to the single wavelength traces obtained by TAS, with the results shown in Scheme 2. As shown in Figure 4, excellent fits to the experimental data were obtained. Several of the steps involving the DCB-radical anion ( $\mathrm{k}_{\text {recomb }}, \mathrm{k}_{\text {recomb2, }} \mathrm{k}_{\text {pair }}$ ) are somewhat faster than our previous measurements in dimethylacetamide. ${ }^{15}$ This may be the result of the lower polarity 2-butanone affording less stabilization to a charged radical. The value of $k_{\text {ox }}$ that we independently obtained from fitting $7( \pm 2) \times 10^{8} \mathrm{M}^{-}$ ${ }^{1} \mathrm{~s}^{-1}$ is in excellent agreement with the value predicted by kinetic modeling. Additions of carbon centered radicals to alkenes have previously been reported in photoredox and related photocatalytic reactions, ${ }^{23,24}$ with rate constants on the order $10^{5}-10^{6} \mathrm{M}^{-1} \mathrm{~s}^{-1},{ }^{25}$ which is in excellent agreement with the value of $\mathrm{k}_{\text {couple }}$ we determined from fitting $\left(1.3( \pm 0.6) \times 10^{5} \mathrm{M}^{-1} \mathrm{~s}^{-1}\right)$.

Kinetic Modeling. Stochastic modeling software was used to calculate the QY based on the rate constants reported in Scheme 2. The photoredox cycle was modeled by first assuming a constant influx of photons based on the photon flux of the light source used for steady state photolysis measurements. Ir(ppy $)_{3}$ was then modeled to absorb a photon of $415 \mathrm{~nm}$ light at a fast enough rate to not impact the overall kinetics. Additionally, potassium carbonate was allowed to act as a base twice and the deprotonated cyanohydrin was also allowed to act as a base, all at a rate of $7.0 \times 10^{8}$ $\mathrm{M}^{-1} \mathrm{~s}^{-1}$. All other kinetic processes were modeled based on the proposed mechanism in Scheme 2.

Without considering any parasitic absorption or quenching by something other than $\mathrm{DCB}$, the modeled quantum yield was nearly 1.0 until the limiting reagent was fully consumed (Figure S10).
This indicates that the inherent kinetics of the reaction are fast enough to convert nearly all absorbed photons into product. Competitive quenching was then incorporated into the model by assuming that cyanohydrin could quench the excited photocatalyst via energy transfer at a rate of $1 \times 10^{9} \mathrm{M}^{-1} \mathrm{~s}^{-1}$. This still gave a QY of nearly 1 at early times (Figure 5, blue trace), with the QY decreasing overtime as the cyanohydrin concentration increased. Finally, parasitic absorption by the thiol $/ \mathrm{K}_{2} \mathrm{CO}_{3}$ species was accounted for by calculating the QY based on the number of photons absorbed solely by the photocatalyst (Figure 5 , orange trace). The result was that the predicted $Q Y$ matched the experimental data significantly better.

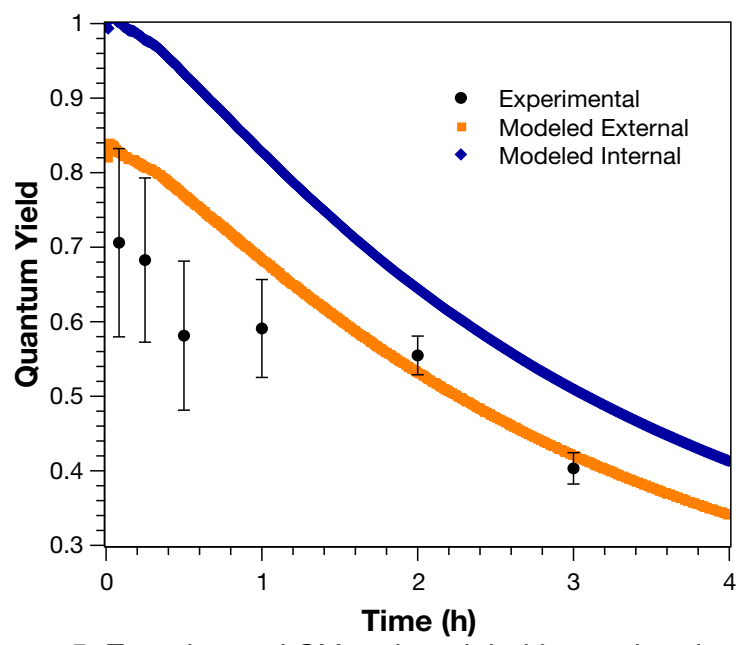

Figure 5. Experimental $Q Y$ and modeled internal and external QY with competitive quenching and parasitic absorption incorporated.

\section{CONCLUSIONS}

Our investigation of an allylic arylation tandem photoredox/HAT reaction reveals a reaction with an initially high QY that steadily decreases over the course of several hours. NMR studies demonstrate the formation of 2-butanone cyanohydrin, likely via nucleophilic attack by cyanide anions discharged in the coupling of cyclohexene and DCB. The deprotonated cyanohydrin in turn appears to play an important role as a base in the reaction. TAS studies of the reaction suggest a previously unrecognized reaction mechanism where HAT is the final step and occurs via a cooperative HAT mechanism with a radical substrate. Kinetic modeling suggests that kinetics of the reaction are sufficiently fast to allow for a $Q Y$ near unity, but that instead the reaction is limited by parasitic absorption and unproductive quenching by the cyanohydrin.

As with our recent report, the presence of a parasitically absorbing species in this reaction 
suggests greater consideration needs to be paid to the impact of unintended reagent absorbances on photoredox reactions. In the case of this reaction, a possible strategy to overcome this may be to shift the wavelength of the light source closer to $400 \mathrm{~nm}$, where the thiol/ $/ \mathrm{K}_{2} \mathrm{CO}_{3}$ species is less absorbing. The use of photocatalysts capable of absorbing in the red would also circumvent this issue and highlights the need for continued development of photocatalysts with a variety of absorption profiles and redox potentials.

While the kinetic modeling suggests we have identified the majority of the productive and unproductive pathways in this reaction, it is important to mention that there may be other deactivation processes we have yet to identify. These pathways may account for the remaining difference between observed and predicted QY. For example, while most of the $\mathrm{K}_{2} \mathrm{CO}_{3}$ dissolves in 2-butanone, we do observe some remains undissolved, which could introduce some scattering losses. Likewise, the $100 \%$ conversion of DCB with an overall percent yield of $87 \%$, implies the existence of a decomposition pathway for DCB that we have not identified. The latter demonstrates the need for continued studies on the stability and decomposition products of cyanoarene radical anions, which are often treated as stable, persistent radicals in reaction design.

\section{EXPERIMENTAL PROCEDURE}

General Information. All reagents except for anhydrous potassium carbonate were obtained from Sigma Aldrich. DCB was crushed with mortar and pestle prior to use. Cyclohexene kept under inert atmosphere and used as received. 2-butanone was dried over molecular sieves. Triisopropylsilane thiol, tetrabutylammonium hexafluorophosphate $\left(\mathrm{TBAPF}_{6}\right)$, and 1,3-Bis(trifluoromethyl)-5-bromobenzene were used as received. Anhydrous potassium carbonate was purchased from Alfa Aesar and used as received. NMR spectra were collected using a Bruker Avance III HD 4.

Steady State Photolysis. A stock solution of cyclohexene, triphenylsilanethiol, and 2-butanone was prepared by combining $10 \mathrm{~mL}$ of 2-butanone, $1 \mathrm{mmol}$ cyclohexene (5 equivs), and $0.0097 \mathrm{mmol}$ triphenylsilanethiol ( 0.05 equivs.). The stock cyclohexene $(0.475 \mathrm{M})$, triphenylsilanethiol (4.83 $\mathrm{mM}$ ), and 2-butanone solution was degassed for 30 minutes with nitrogen gas while submerged in an ice water bath. A 2-sided quartz screw top cuvette was charged with $0.19 \mathrm{mmol}$ DCB (1 equivs.), $1.9 \mu \mathrm{mol} \quad$ tris[2-phenylpyridinato-
$\mathrm{C}^{2}, \mathrm{~N}$ ]iridium(III) (0.01 equivs), and $9.5 \mu \mathrm{mol}$ potassium carbonate ( 0.05 equivs.), a magnetic stirring flea, and $2 \mathrm{~mL}$ of previously degassed cyclohexene/triphenylsilanethiol/2-butanone solution. The combined reaction mixture was degassed for an additional 45 minutes with nitrogen gas while submerged in an ice water bath. After degassing, the reaction mixture was illuminated for a specified amount of time $(0.25-24 \mathrm{hr})$ with a collimated $415 \mathrm{~nm}$ LED (Thor Labs M15LP1). Once the illumination time elapsed, $0.25 \mathrm{mmol}$ of internal standard, 1,3-Bis(trifluoromethyl)-5-bromobenzene, was added to the solution and stirred for 15 additional minutes in the dark. Product yields were determined using quantitative HNMR with 1,3-Bis(trifluoromethyl)-5-bromobenzene as an internal standard.

The quantum yield of reaction was calculated as follows:

$$
\emptyset_{\text {reaction }}=\frac{n_{\text {product }} N_{A} h c}{t f P \lambda}
$$

where $\mathrm{n}_{\text {product }}$ is the product yield, $\mathrm{N}_{\mathrm{A}}$ is Avogadro's number $\left(6.022 \times 10^{23} \mathrm{~mol}^{-1}\right)$, $\mathrm{h}$ is Planck's constant $\left(6.626 \times 10^{-34} \mathrm{~J}^{*} \mathrm{~s}\right), \mathrm{c}$ is the speed of light in a vacuum $\left(2.998 \times 10^{8} \mathrm{~m} / \mathrm{s}\right), \mathrm{f}$ is the fraction of light absorbed at the chosen wavelength with absorbance $A\left(f=1-10^{-A}\right)$, $t$ is the illumination time in seconds, $\mathrm{P}$ is the total power for the detector area $(\mathrm{W})$, and $\lambda$ is the chosen wavelength $(\mathrm{m})$. The photon flux of the $415 \mathrm{~nm}$ LED was determined using was determined using a Thorlabs powermeter attached to a photodetecting plate with a $1 \mathrm{~cm}$ diameter.

Stern-Volmer Emission Quenching. SternVolmer emission quenching studies were carried out using a Shimadzu RF-6000 Spectrofluorophotometer. The absorbance of each solution was checked prior to collecting emission spectra using a Shimadzu UV-2600 Spectrophotometer to ensure uniformity in concentrations of photocatalyst. A stock solution of $35 \mu \mathrm{M} \operatorname{Ir}(\mathrm{ppy})_{3}$ was utilized for all experiments. Stern-Volmer experiments were carried out with $150 \mathrm{mM} \mathrm{DCB}, 100 \mathrm{mM} \mathrm{Ph}_{3} \mathrm{SiSH}$, and $100 \mathrm{mM} \mathrm{Ph}_{3} \mathrm{SiSH}$ combined with $100 \mathrm{mM}$ $\mathrm{K}_{2} \mathrm{CO}_{3}$. Excitation spectra were collected at an excitation wavelength of $415 \mathrm{~nm}$ and $\mathrm{I}$ and $\mathrm{I}_{\mathrm{o}}$ were determined at an emission wavelength of $570 \mathrm{~nm}$.

Electrochemical Measurements. Electrochemical measurements were carried out using a BioLogic SP-50 potentiostat and a Pine rotating disk electrode cell with waterjacket. A pseudo$\mathrm{Ag} / \mathrm{AgCl}$ reference electrode and gold working electrode were utilized. All measurements were carried out in 0.1 $\mathrm{M} \mathrm{TBAPF}_{6}$ in 2-butanone as an electrolyte. The solvent window was determined prior to experiments with reaction substrates. 
Cyclic voltammetry was referenced to ferrocene $\left(\mathrm{Fc} / \mathrm{Fc}^{+}\right)$. For cyclic voltammetry with triphenylsilanethiol, $0.1462 \mathrm{~g}$ of thiol was dissolved in 50 $\mathrm{mL}$ of $0.1 \mathrm{M}$ TBAPF6. The potential window was cut off prior to solvent oxidation in order to probe for reversible peaks. Cyclic voltammetry was carried out with equimolar amounts of thiol and $\mathrm{K}_{2} \mathrm{CO}_{3}$ dissolved in $0.1 \mathrm{M} \mathrm{TBAPF}_{6}$ in 2-butanone and stirred for 10 minutes prior to collecting a cyclic voltammogram (CV).

TAS Measurements. Transient absorption spectra were collected using a custom-built spectrometer described in reference 12. An excitation wavelength of $415 \mathrm{~nm}\left(1.0 \mathrm{~mJ} / \mathrm{cm}^{2}\right)$ was used for all experiments. Wavelength traces for the full reaction mixture were collected at wavelengths from 400-800 nm and from $200 \mathrm{~ns}$ to $10 \mathrm{~ms}$. TAS samples were prepared by combining $100 \mathrm{mM}$ of DCB, $5 \mathrm{mM}$ triphenylsilanethiol, $5 \mathrm{mM}$ potassium carbonate, $500 \mathrm{mM}$ cyclohexene and $3 \mathrm{~mL}$ of 35 $\mu \mathrm{M} \operatorname{Ir}($ ppy)3 stock solution in 2-butanone in a foursided glass screw top cuvette. The cuvette was charged with a magnetic stirring flea and degassed with nitrogen for 1 hour while partially submerged in an ice-water bath to prevent evaporation of cyclohexene and 2-butanone. After degassing, the solution was stirred in the dark for 15 minutes to ensure homogeneity of the reaction mixture. Samples were changed every two hours and the stability of each solution was verified by collecting wavelength traces at the same wavelength before and after the two hours.

Kinetic Modeling. Kinetic modeling software Kinetiscope was utilized to create a stochastic model of the reaction (Figure S11). Simulations were set to match concentrations in experimental reactions and contain $10^{8}$ particles with $1.981 \mathrm{x}$ $10^{-7} \mathrm{~mol} /$ particle. Equilibrium detect was enabled with a test cycle length of 100 events and a selection frequency of $90.0 \%$. Pressure, volume, and temperature were all set at standard conditions. A constant influx of photons was modeled by allowing a zeroth order reaction to proceed where an arbitrary species W was transformed to hv (symbolizing a $415 \mathrm{~nm}$ photon) at a constant rate equal to the moles of photons/s being absorbed by $\operatorname{Ir}(\mathrm{ppy})_{3}$. Ir(ppy $)_{3}$ was then set to absorb a photon at a rate of $1 \times 10^{20} \mathrm{M}^{-1} \mathrm{~s}^{-1}$ as to be essentially instantaneous and not interfere with the overall kinetics of the reaction. $\operatorname{Ir}(\mathrm{ppy})_{3}{ }^{*}$ was modeled to emit an unproductive photon at a rate corresponding to the rate of radiative decay calculated from the phosphorescence lifetime of $\operatorname{Ir}(\mathrm{ppy})_{3}{ }^{*} . \mathrm{K}_{2} \mathrm{CO}_{3}$ was modeled as being able to act as a base twice due to carbonate having a charge of -2 , with both deprotonations occurring at a rate of $7 \times 10^{8} \mathrm{M}^{-1} \mathrm{~s}^{-}$
1. The anionic cyanohydrin was also modeled to deprotonate the thiol in the reaction via PCET with the oxidized photocatalyst at a rate of $7 \times 10^{8} \mathrm{M}^{-1}$ $\mathrm{s}^{-1}$. Deprotonation reactions were modeled as being first order in $\mathrm{Ph}_{3} \mathrm{SiSH}$ and $\operatorname{Ir}(\mathrm{ppy})_{3}{ }^{+}$as PCET would likely involve a pre-association of $\mathrm{Ph}_{3} \mathrm{SiSH}$ and $\mathrm{K}_{2} \mathrm{CO}_{3}$ or the cyanohydrin. The protonated cyanohydrin was modeled to deactivate the excited photocatalyst via energy transfer at a rate of $1 \times 10^{9} \mathrm{M}^{-1} \mathrm{~s}^{-1}$. A final step was added to allow the excited cyanohydrin to relax back to the ground state at a rate of $1 \times 10^{10} \mathrm{~s}^{-1}$. The remainder of the kinetic model was created to represent the mechanism seen in Scheme 2.

\section{ASSOCIATED CONTENT}

\section{Supporting Information}

The Supporting Information is available free of charge on the ACS Publications website. (PDF)

\section{AUTHOR INFORMATION}

\section{Corresponding Author}

*E-mail: jswierk@binghamton.edu

\section{ACKNOWLEDGMENT}

This work was supported by the National Science Foundation (Award Number CHE-2047492). BGS and MJS also thank the Department of Chemistry for summer fellowships.

\section{REFERENCES}

1. Yoon, T. P.; Blum, T. R.; Skubi, K. L. Dual Catalysis Strategies in Photochemical Synthesis. Chem. Rev. 2016, 116 (17), 10035-10074 DOl: 10.1021/acs.chemrev.6b00018

2. MacMillan, D. W. C.; Rankic, D. A.; Qvortrup, K. A General Strategy for Organocatalytic Activation of $\mathrm{C}-\mathrm{H}$ Bonds via Photoredox Catalysis: Direct Arylation of Benzylic Ethers. J. Am. Chem. Soc. 2014, 136 (2), 626-629. DOI: $10.1021 / \mathrm{ja} 411596 \mathrm{q}$

3. Nocera, D. G.; Schnedermann, C.; Qin, Y.; Ruccolo, S. General Strategy for Improving the Quantum Ef-ficiency of Photoredox Hydroamidation Catalysis. J. Am. Chem. Soc. 2018, 140 (44), 14926-14937. DOI: 10.1021/jacs.8b09109

4. Qin, Y.; Zhu, Q.; Sun, R.; Jacob, M. G.; Knowles, R. R.; Nocera, D. G. Mechanistic Investigation and Optimization of Photoredox Anti-Markovnikov Hydroamination. J. A.. Chem. Soc. 2021, 143 (27), 10232-10242. DOI: 10.1021/jacs.1c03644

5. MacMillan, D. W. C.; Cuthbertson, J. D. The direct arylation of allylic sp3 $\mathrm{C}-\mathrm{H}$ bonds via organic and photoredox catalysis. Nature. 2015, 519, 74-77 DOI: 10.1038/nature14255

6. Becker, P.; Duhamel, T.; Stein, C. J.; Reiher, M.; Muniz, K. Cooperative Light-Activated lodine and Photoredox Catalysis for the Amination of $\mathrm{C}_{\mathrm{sp} 3}-\mathrm{H}$ Bonds Angew. Chem. Int. Ed. 2017, 56, 8004-8008. DOI: 10.1002/anie.201703611

7. Shaw, M. H.; Shurtleff, V. W.; Terrett, J. A.; Cuthbertson, J. D.; MacMillan, D. W. C. Native functionality in triple catalytic cross-coupling: $\mathrm{sp}^{3} \mathrm{C}-\mathrm{H}$ bonds as latent 
nucleophiles Science 2016, 352 (6291), 1304-1308. DOI: $10.1126 /$ science.aaf6635

8. Lewis-Borrell, L.; Sneha, M.; Bhattacherjee, A.; Clark, I. P.; Orr- Ewing, A. J. Mapping the Multi-step Mechanism of a Photoredox Catalyzed Atom-Transfer Radical Polymerization Reaction by Direct Observation of the Reactive Intermediates. Chem. Sci. 2020, 11, 4475-4481. DOI: 10.1039/d0sc01194k

9. Koyama, D.; Dale, D. J. A.; Orr-Ewing, A. J. Ultrafast Observation of a Photoredox Reaction Mechanism: Photoinitiation in Organocatalyzed Atom-Transfer Radical Polymerization. J. Am. Chem. Soc. 2018, 140 (4), 1285-1293. DOI: 10.1021/jacs.7b07829

10. Martinez-Haya, R.; Miranda, M. A.; Marin, M. L. MetalFree Photocatalytic Reductive Dehalogenation Using Visible-Light: A Time-Resolved Mechanistic Study. Eur. J. Org. Chem. 2017, 2017 (15), 2164-2169. DOI: 10.1002/ejoc.201601494

11. Rueda-Becerril, M.; Mahé, O.; Drouin, M.; Majewski, M. B.; West, J. G.; Wolf, M. O.; Sammis, G. M.; Paquin, J.F. Direct C-F Bond Formation Using Photoredox Catalysis. J. Am. Chem. Soc. 2014, 136 (6), 2637-2641. DOI: 10.1021/ja412083f

12. Ting, S. I.; Garakyaraghi, S.; Taliaferro, C. M.; Shields, B. J.; Scholes, G. D.; Castellano, F. N.; Doyle, A. G. ${ }^{3} \mathrm{~d}-$ d Excited States of Ni(II) Complexes Relevant to Photoredox Catalysis: Spectroscopic Identification and Mechanistic Implications. J. Am. Chem. Soc. 2020, 142 (12), 5800-5810. DOI: 10.1021/jacs.0c00781

13. Zheng, S.; Zhang, S.-Q.; Saeednia, B.; Zhou, J.; Anna, J. M.; Hong, X.; Molander, G. A. Diastereoselective Olefin Amidoacylation via Pho-toredox PCET/Nickel-Dual Catalysis: Reaction Scope and Mechanistic Insights. Chem. Sci. 2020, 11, 4131-4137. DOI: 10.1039/d0sc01459a

14. Coles, M. S.; Quach, G.; Beves, J. E.; Moore, E. G. A Photophysical Study of the Sensitization-Initiated Electron Transfer: Insights into the Mechanism of Photoredox Activity. Angew. Chem., Int. Ed. 2020, 59 (24), 9522-9526. DOI: 10.1002/anie.201916359

15. Stevenson, B. G.; Spielvogel, E. H.; Loiaconi, E. A.; Wambua, V. M.; Nakhamiyayev, R. V.; Swierk, J. R.; Mechanistic Investigations of an a-Aminoarylation Photoredox Reaction J. Am. Chem. Soc. 2021, 143 (23), 8878-8885. DOI: 10.1021/jacs.1c03693

16. Huang, L.; Rueping, M. Direct Cross-Coupling of Allylic $\mathrm{C}\left(\mathrm{sp}^{3}\right)-\mathrm{H}$ Bonds with Aryl- and Vinylbromides by Combined Nickel and Visible-Light Catalysis Angew. Chem. Int. Ed. 2018, 57 (32), 10333-10337. DOI: 10.1002/anie.201805118

17. Pal, S.; Cotard, M.; Géradin, B.; Hoarau, C.; Schneider, C. Cu-Catalyzed Oxidative Allylic C-H Arylation of Inexpensive Alkenes with (Hetero)Aryl Boronic Acids Org. Lett. 2021, 23 (8), 3130-3135. DOI: 10.1021/acs.orglett.1c00812

18. Xu, W.; Wang, W.; Liu, T.; Xie, J.; Zhu, C. Late-stage trifluoromethylthiolation of benzylic $\mathrm{C}-\mathrm{H}$ bonds Nat. Commun. 2019, 10, 4867. DOI: 10.1038/s41467-01912844-9

19. Dethe, D. H.; Srivastava, A.; Derange, B. D.; Kumar, B. V. Unsymmetrical Disulfide Synthesis through Photoredox Catalysis Adv. Synth. Catal. 2018, 360 (16), 30203025. DOI: 10.1002/adsc.201800405

20. Lei, Z.; Banerjee, A.; Kusevska, E.; Rizzo, E.; Liu, P.; Ngai, M. Y. $\beta$-Selective Aroylation of Activated Alkenes by Photoredox Catalysis Angew. Chem. Int. Ed. 201958 (22), 7318-7323. DOI: 10.1002/anie.201901874

21. Kanda, T.; Naraoka, A.; Naka, H. Catalytic Transfer Hydration of Cyanohydrins to a-Hydroxyamides. J. Am.
Chem. Soc. 2019, 141 (2), 825-830. DOI: $10.1021 /$ jacs.8b12877

22. Kattamuri, P.V.; West, J.G. Cooperative Hydrogen Atom Transfer: From Theory to Application. Synlett. 2021, 32 (12), 1179-1186. DOI: 10.1055/a-1463-9527

23. Rawner, T.; Lutsker, E.; Kaiser, C. A.; Reiser, O. The Different Faces of Photoredox Catalysts: Visible-LightMediated Atom Transfer Radical Addition (ATRA) Reactions of Perfluoroalkyl lodides with Styrenes and Phenylacetylenes. ACS Catal. 2018, 8 (5), 3950-3956 DOI: 10.1021/acscatal.8b00847

24. Tang, X. J.; Dolbier, W. R. Efficient Cu-catalyzed Atom Transfer Radical Addition Reactions of Fluoroalkylsulfonyl Chlorides with Electron-deficient Alkenes Inducedby Visible Light. Angew. Chem. Int. Ed. 2015, 54 (14), 4246-4249. DOI: 10.1002/anie.201412199

25. Beckwith, A. L. J.; Poole, J. S. Factors Affecting the Rates of Addition of Free Radicals to Alkeness Determination of Absolute Rate Co-efficients Using the Persistent Aminoxyl Method. J. Am. Chem. Soc. 2002, 124 (32), 9489-9497. DOI: 10.1021/ja025730g 